\title{
FAT1 inhibits cell migration and invasion by affecting cellular mechanical properties in esophageal squamous cell carcinoma
}

\author{
XIAOLING HU ${ }^{1-3^{*}}$, YUANFANG ZHAI ${ }^{1,2,4^{*}}$, RUYI SHI $^{1,2^{*}}$, YU QIAN $^{1,2^{*}}$, HEYANG CUI $^{1,2}$, JIE YANG $^{1,2}$, \\ YANGHUI BI ${ }^{1,2}$, TING YAN ${ }^{1,2}$, JIAN YANG ${ }^{1,2}$, YANCHUN MA ${ }^{1,2}$, LING ZHANG ${ }^{1,2}$, YIQIAN LIU ${ }^{1,2}$, \\ GUODONG LI $^{5}$, MINGSHENG ZHANG ${ }^{3}$, YONGPING CUI ${ }^{1,2}$, \\ PENGZHOU KONG $^{1,2}$ and XIAOLONG CHENG ${ }^{1,2,4}$ \\ ${ }^{1}$ Translational Medicine Research Center, Shanxi Medical University; ${ }^{2}$ Key Laboratory of Cellular Physiology, \\ Ministry of Education; Departments of ${ }^{3}$ Pharmacology and ${ }^{4}$ Anatomy, Shanxi Medical University; \\ ${ }^{5}$ Department of Otorhinolaryngology, Shanxi Provincial People's Hospital, \\ Taiyuan, Shanxi 030001, P.R. China
}

Received August 25, 2017; Accepted March 8, 2018

DOI: $10.3892 / o r .2018 .6328$

\begin{abstract}
FAT atypical cadherin 1 (FAT1) belongs to the cadherin superfamily and has been reported to regulate cell-cell adhesion and other cell behaviors, suggesting its pivotal roles in human cancers. We previously identified FAT1 as one of the significant mutant genes in esophageal squamous cell carcinoma (ESCC). In the present study, the knockdown of FAT1 expression in YSE2 and Colo680N cell lines was carried out by lentivirus, and we found that knockdown of FAT1 led to acceleration of cell migration and invasion. Furthermore, we detected the cell adhesive force and cell elasticity force by atomic force microscopy (AFM) and found that the suppression of endogenous expression of FAT1 led to a decrease in the cell adhesive force and increase in the cell elasticity force compared with the control groups. In conclusion, our study demonstrated that FAT1 altered cellular mechanical properties leading to deregulation of cell migration and invasion of ESCC, which may be a novel target for ESCC therapy.
\end{abstract}

\section{Introduction}

The incidence and mortality rate of esophageal cancer (EC) are ranked as the eighth and sixth highest among all cancers

Correspondence to: Dr Pengzhou Kong or Professor Xiaolong Cheng, Translational Medicine Research Center, Shanxi Medical University, 56 Xin Jian Nan Road, Taiyuan, Shanxi 030001, P.R. China

E-mail: kongpengzhou@sxmu.edu.cn

E-mail: chengxl@sxmu.edu.cn

${ }^{*}$ Contributed equally

Key words: esophageal squamous cell carcinoma, FAT1, migration, invasion, cell mechanical properties worldwide (1). China is one of the countries with the highest incidence and mortality of EC in the world. Newly diagnosed EC cases are estimated at 4,292,000 annually, ranking as the third among all cancer cases, and accounting for 2,814,000 cancer-related deaths, which ranks fourth among all cancer cases (2). It is widely known that the Taihang Mountain region is an area with a high incidence of EC cases located in the junction of Shanxi, Hebei and Henan Province (3). Esophageal squamous cell carcinoma (ESCC) is the main type of EC and $\sim 70 \%$ of worldwide ESCC cases occur in China. The 5-year survival rate of ESCC remains between 10 and $25 \%$ due to the absence of clinical approaches for early diagnosis and treatment $(4,5)$. Therefore, identification of the critical driving genes of ESCC is urgent in order to improve the management of ESCC patients.

In ourpreliminary experiment, we performed whole-genome sequencing (WGS) of 14 and whole-exome sequencing (WES) of 90 ESCC tumor and adjacent normal tissues from patients recruited from the Taihang Mountain region in China. We identified eight significantly mutated genes (SMGs) including FAT atypical cadherin 1 (FAT1). Among these SMGs, FAT1 was mutated in $15 \%$ of ESCC tumors $(6,7)$. Furthermore, our studies identified a novel role for FAT1 in inhibiting tumor growth and epithelial-mesenchymal transition (EMT) in ESCC by disrupting the MAPK/ERK pathway (8).

Fat cadherins are extremely large cell adhesion molecules, with $>30$ cadherin repeats, including FAT1, FAT2, FAT3, FAT4. FAT1 is an important trans-membrane protein involved in the regulation of cell adhesion and growth, migration, actin dynamics and orientation, playing critical roles in tumor development. It is often regarded as a tumor-suppressor gene or oncogene in different types of human cancer (9-11). Morris et al reported that recurrent somatic mutation of FAT1 was found to lead to aberrant activation of the Wnt/ $\beta$-catenin signaling pathway in human glioblastoma multiforme (12). Moreover, depression of FAT1 was found to accelerate cell migration in cholangiocarcinoma and breast cancer (13). 
However, it was reported that FAT1 acts as an oncogene in hepatic cancer (11). Noteworthy, our previous study showed that FAT1 acts as a tumor-suppressor gene in ESCC (8).

Atomic force microscopy (AFM) has provided a new screening test to observe the morphological and mechanical properties of a single cell (14). AFM is a type of scanning probe microscopy with high resolution, that can be used to detect changes in cellular biophysical properties, such as roughness, adhesion and elasticity $(15,16)$. With the development of AFM technology, AFM is used more and more extensively in the tumor field. Kaul-Ghanekar et al observed and analyzed breast cancer cell lines by AFM and found that SMAR1 acts as tumor suppressor by regulating expression of cell surface proteins (17). Cross et al reported the stiffness of live metastatic cancer cells taken from the pleural fluids of patients with suspected lung, breast and pancreas cancer. The results showed that mechanical analysis can distinguish cancer cells from normal cells using AFM (18).

The aim of our present study was to confirm the effect of FAT1 on the migration and invasion of ESCC cell lines YSE2 and Colo680N. Moreover, the cell adhesive force and cell elasticity force after FAT1 knockdown were detected by AFM. The present study will contribute to the understanding of the mechanisms that drive the development and progression of ESCC and may provide a new therapeutic target for ESCC treatment.

\section{Materials and methods}

Cell culture. All ESCC cell lines used in the study were obtained from the Translational Medicine Research Center, Shanxi Medical University (Taiyuan, China) and cultured in HyClone ${ }^{\mathrm{TM}}$ RPMI-1640 medium (GE Healthcare Life Sciences, HyClone Laboratories, Logan, UT, USA) with $10 \%$ fetal bovine serum (FBS; Gibco; Thermo Fisher Scientific, Inc., Waltham, MA, USA) at $37^{\circ} \mathrm{C}$ in a $5 \% \mathrm{CO}_{2}$ incubator. Culture medium was replaced every two to three days. Subculture was carried out when the cells were fused to $80-90 \%$ confluency and logarithmic phase cells were used in the following experiments.

Ethics statement. All experimental protocols were approved by the Ethics Committee of Shanxi Medical University. All samples were obtained before treatment according to the guidelines of the local ethics committees and written informed consent was received from all participants.

TMAs and immunohistochemistry (IHC). Tissue microarrays (TMAs) consisting of 125 primary ESCC tumor tissues and 125 matched non-tumor tissues were obtained from Shanxi Cancer Hospital from 2011 to 2014. IHC was performed to detect the protein expression of the corresponding genes. Briefly, the TMA sections $(4 \mu \mathrm{m})$ were deparaffinized and rehydrated with xylene and a series of grades of alcohol and then soaked in 3\% $\mathrm{H}_{2} \mathrm{O}_{2}$ for $15 \mathrm{~min}$. Antigen retrieval was implemented in sodium citrate buffer ( $\mathrm{pH}$ 6.0) for $2 \mathrm{~min}$ in a pressure cooker, followed by incubation with the anti-FAT1 antibody (1:300 dilution; rabbit polyclonal antibody; cat. no. HPA023882; Sigma-Aldrich; Merck KGaA, Darmstadt, Germany) at $4^{\circ} \mathrm{C}$ overnight. After washing with PBS, the TMA sections were incubated with the secondary antibody (HRP-polymer anti-mouse/rabbit IHC kit, goat; cat. no. KIT-5920; Maixin Biotechnology, Co., Ltd., Fuzhou, China) at $37^{\circ} \mathrm{C}$ for $20 \mathrm{~min}$. Slides were stained with DAB and counterstained with hematoxylin. The levels and location of FAT1 were assessed using IHC and analyzed with Aperio Cytoplasma 2.0 software (Leica Microsystems GmbH, Wetzlar, Germany). The protein expression of FAT1 was calculated by a semi-quantitative assessment of both the staining intensity and the percentage of positive cells.

$R N A$ extraction and reverse transcription PCR (RT-PCR) and quantitative real-time PCR ( $P P C R)$. Total RNA was isolated from cells by TRIzol reagent (Takara Biotechnology Co., Ltd., Dalian, China). RNA (2 $\mu \mathrm{g})$ was reverse-transcribed in $20 \mu \mathrm{l}$ using the PrimeScript ${ }^{\circledR}$ RT Master Mix (Perfect Real-Time) for RT-PCR (Takara Biotechnology). The reaction conditions of reverse-transcription PCR were set as follows: $94^{\circ} \mathrm{C}$ for $5 \mathrm{~min}$, 30 cycles at $94^{\circ} \mathrm{C}$ for $50 \mathrm{sec}, 55^{\circ} \mathrm{C}$ for $30 \mathrm{sec}$, and $72^{\circ} \mathrm{C}$ for $50 \mathrm{sec}$; followed by extension at $72^{\circ} \mathrm{C}$ for $10 \mathrm{~min}$. Quantitative real-time PCR (qPCR) experiment was implemented with SYBR $^{\circledR}$ Premix Ex Taq ${ }^{\mathrm{TM}}$ (Takara Biotechnology). The detailed protocol was as follows: $95^{\circ} \mathrm{C}$ for $10 \mathrm{~min}, 40$ cycles of $95^{\circ} \mathrm{C}$ for $15 \mathrm{sec}$, and $60^{\circ} \mathrm{C}$ for $1 \mathrm{~min}$. The relative expression of target genes was determined by normalization to GAPDH expression and was determined as $\Delta \Delta \mathrm{Ct}$. The primers used to measure the expression level of FAT1 were: 5'-TGCTGGA GGAAAAGTTGCTT-3' (sense), and 5'-GATTACGCCGGA CAGTTTGT-3' (antisense). The primers of GAPDH were: 5'-AGTCAACGGATTTGGTCGTA-3' (sense), and 5'-AGT CAACGGATTTGGTCGTA-3' (antisense). The experiment was completed in triplicate independently.

In-cell western assay. The FAT1 protein in the ESCC cell lines was determined using in-cell western assay. Briefly, $4 \times 10^{4}$ cells were seeded in 96-well plates and incubated under normal conditions to culture to a final volume of $200 \mu \mathrm{l} /$ well overnight. The cells were fixed with $4 \%$ formaldehyde and permeabilized using $0.2 \%$ Triton X-100. LI-COR Odyssey Blocking Buffer (150 $\mu \mathrm{l}$ ) (LI-COR Biosciences, Lincoln, NE, USA) was added to each well. The cells were then incubated with the FAT1 primary antibody $(1: 1,000$; rabbit polyclonal antibody; cat. no. ab190242; Abcam, Cambridge, UK). Then, the wells were incubated with corresponding fluorescence stain CellTag $^{\text {TM }} 700$ Stain (red fluorescence; LI-COR Biosciences, Lincoln, NE, USA) or fluorescence antibody IRDye ${ }^{\mathrm{TM}}$ 800CW (green fluorescence; LI-COR Biosciences). Images of FAT1 were obtained using the Odyssey Infrared Imaging System (LI-COR Biosciences GmbH, Bad Homburg, Germany). The protein level of FAT1 was calculated as the ratio of the intensity of FAT1 to that of the cell number. At least three independent experiments were carried out; for each independent experiment, three duplicates were performed for each group.

Plasmid constructs and transfection. For knockdown of endogenous FAT1, we used vectors containing the sequence: 5'-GCCTGTGGGTTCCAGTGTAAT-3' (FAT1shRNA1) and 5'-GCTGGAAATGAACTGGATTTC-3' (FAT1shRNA1) and scramble control sequence: 5'-TTCTCCGAACGTGTCACG TTTC-3' (NC). These shRNAs were cloned into the vector 
pGLV-H1-GFP+Puro and co-transfected into 293T cells with packaging plasmids (Shanghai GenePharma Co., Ltd., Shanghai, China). The lentivirus supernatant was used to infect the YSE2 and Colo680N cell lines. The corresponding empty vectors were used as the negative control. Stable cell lines were screened out for 2 weeks with $2 \mu \mathrm{g} / \mathrm{ml}$ puromycin (Invitrogen; Thermo Fisher Scientific, Inc.). The efficiency of silence was determined by means of RT-PCR, qPCR and in-cell western assay.

Transwell migration and invasion assays. Migration and invasion assays were performed using Transwell plates (pore size is 8- $\mu \mathrm{m}$; Corning, Inc., Corning, NY, USA). In brief, 50,000 cells were seeded into each well with serum-free medium in the upper compartment of the Transwell plates coated with or without BD Matrigel Basement Membrane Matrix (BD Biosciences, Franklin Lakes, NJ, USA), and the ratio of the Matrigel Basement Membrane Matrix and serum-free medium was 1:6. The lower compartment of the chamber was filled with medium with $10 \%$ FBS. Following a 24 -h culture, the cell numbers that passed through the membrane were fixed with $4 \%$ formaldehyde and stained using $0.1 \%$ crystal violet and counted under a microscope (IX71-A12FL/PH; Olympus Corp., Tokyo, Japan).

Wound healing assay. The stably transfected YSE2 and Colo680N cells were seeded in 6-well plates. When cells grew to $95-100 \%$ density, the cell monolayer was scratched using a pipette tip, followed by being washed with culture medium to remove any loosely held cells. The wound closure was monitored at 0 and $24 \mathrm{~h}$ after scratching, and the wound area was calculated using ImageJ software (National Institutes of Health, Bethesda, MD, USA). At least three independent experiments were carried out; for each independent experiment, three duplicates were performed for each group.

Atomic force microscopy (AFM) analysis. The morphology and biomechanical properties of the YSE2-FAT1shRNA and Colo680N-FAT1shRNA cells and the corresponding controls were detected by AFM, as previously described (19). Briefly, AFM images were acquired in the tapping mode and in contact mode using Si3N4 tips (NSC19, $0.68 \mathrm{~N} / \mathrm{m}$ normal spring constant; Schaefer Technologie GmbH, Langen, Germany) and gold-coated tips (CSC 38; Schaefer Technologie GmbH), respectively. AFM measurements were performed in aqueous solution at room temperature, using a 5500 atomic force microscope (Agilent Technologies, Inc., Santa Clara, CA, USA). The spring constants of the cantilevers used for AFM force spectroscopy were $\sim 0.1 \mathrm{~N} / \mathrm{m}$. Adhesion and elasticity maps were obtained by recording $16 \times 16$ force-distance curves on areas of a given size $(2 \times 2 \mu \mathrm{m})$, calculating the adhesion force and elasticity modulus for each force curve and displaying these values as gray and colorized scale pixels, respectively. These maps qualitatively and quantitatively demonstrated the viscoelasticity of individual cells at the nanoscale level.

Statistical analyses. Statistical analyses were performed using SPSS 18.0 software (SPSS, Inc., Chicago, IL, USA). Experiments were performed in triplicate, and data are presented as the mean \pm SEM. Data from two groups were analyzed by unpaired t-test and $>2$ groups were analyzed by one-way ANOVA with post hoc contrasts by the S-N-K method. A P-value of $<0.05$ was considered to indicate a statistically significant difference.

\section{Results}

FAT1 exhibits a high frequency of mutations and shows downregulated expression in ESCC. In our previous study, we analyzed the genomic sequencing data from 4 ESCC cohorts, including 424 tumors and matched normal DNA samples, from patients recruited in the Taihang Mountain region of north-central China and Chaoshan District of Guangdong Province, the areas of high ESCC incidence in China. We found that FAT1 was mutated frequently in ESCC. The total mutation rate was $\sim 13.4 \%$ (57/424), including nonsense in $21 / 57(36.8 \%)$, missense in 22/57 (38.6\%), insertion or deletion in $14 / 57(24.6 \%)$ in these 4 cohorts $(6,8,20-22)$. In addition, we analyzed several types of squamous cell carcinomas in a TCGA database using cBioPortal $(23,24)$, and found that FAT1 was mutated frequently in squamous cell carcinomas (Fig. 1A). In ESCC, the frequency of FAT1 mutations was $11.7 \%$ (20), in head and neck squamous cell carcinoma (HNSCC), the frequency of FAT1 mutations was $21.7 \%$ (23), in lung squamous cell carcinoma (LSCC), the frequency of FAT1 mutations was $14.6 \%$ (25), and in oral squamous cell carcinoma (OSCC), the frequency of FAT1 mutations was $30 \%$ (26). Then, we detected FAT1 protein expression via TMA that included 76 cases of primary esophageal tumor tissues and matched adjacent non-tumor tissues, since the other 49 cases of tissues were incomplete for further statistics. We observed that FAT1 expression was strongly lower in the tumor tissues than that noted in the stained non-tumor tissues (Fig. 1B). Data on the 125 patients from which the tumor and normal samples were derived for the TMA study are provided in Table I.

Knockdown of FAT1 in ESCC cells. First, we measured FAT1 mRNA levels in non-transformed esophageal epithelial SHEE cells and 8 ESCC cell lines by RT-PCR and in-cell western assay and found different expression levels in the various of ESCC cell lines (Fig. 2A and B). Of these cell lines, YSE2 and Colo680N cell lines with a relative high endogenous FAT1 level were used for the knockdown experiment. The transfection efficiency of YSE2 and Colo680N cells was $>90 \%$ (Fig. 2C). RT-PCR and qPCR were used to assess the mRNA expression of FAT1 in the FAT1-knockdown ESCC cells (Fig. 2D). In-cell western assay was used to assess the protein of FAT1 in FAT1-knockdown ESCC cells (Fig. 2E). The data showed that the efficiency of knockdown was $>70 \%$.

FAT1 knockdown promotes cell migration and invasion in ESCC. Transwell assays were performed to examine the effect of FAT1 on the migration and invasion of ESCC cells. The results showed that FAT1 depletion led to a significant increase in cell migration and invasion abilities in the YSE2 and Colo680N cell lines (Fig. 3A and B), which were also confirmed by the wound healing migration assay (Fig. 3C).

Changes in the morphologic and biomechanical properties of the ESCC cells after FAT1 knockdown as determined by 

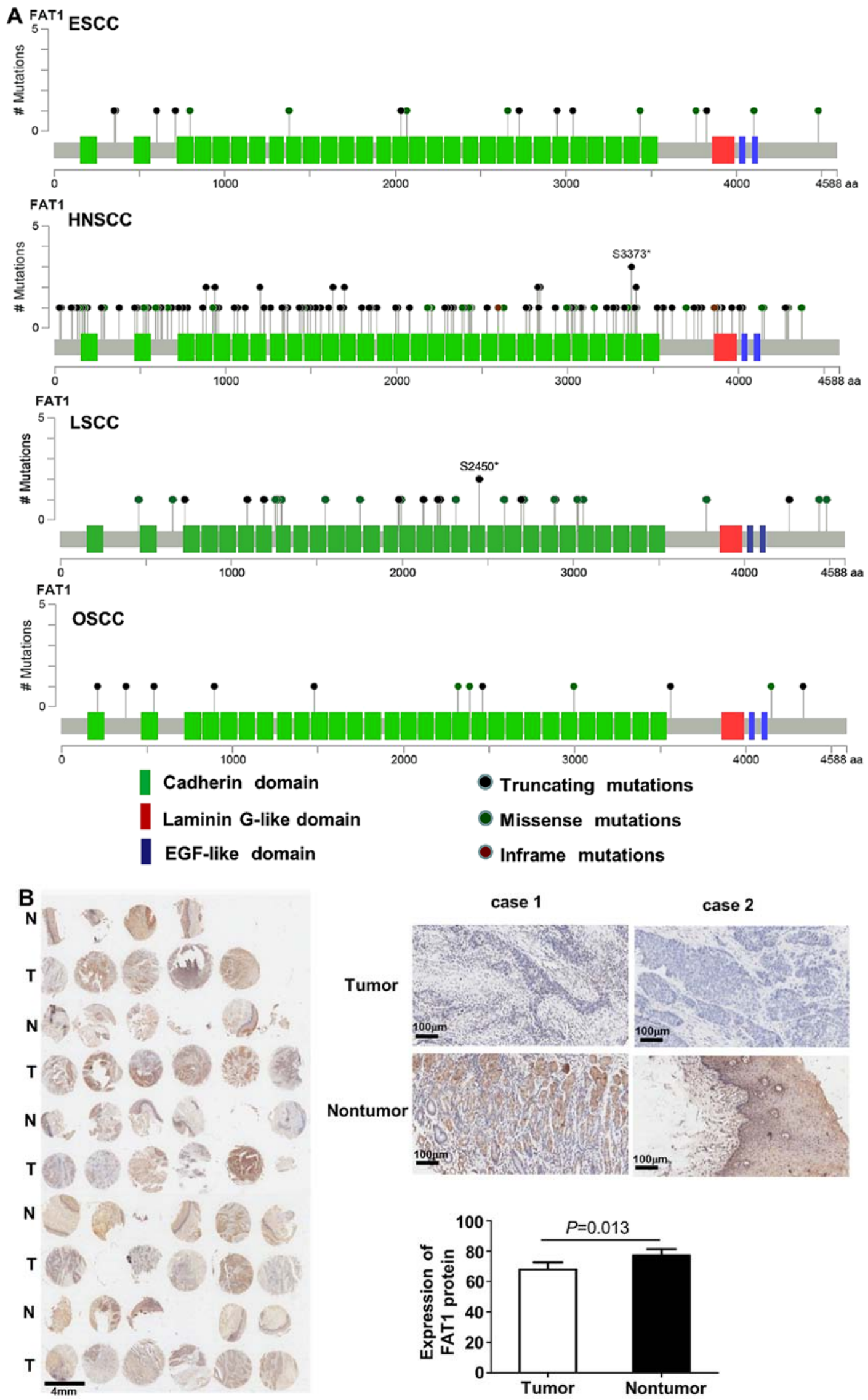

Figure 1. FAT1 mutations frequently occur in ESCC and other squamous cell carcinomas, and FAT1 exhibits downregulated expression in ESCC. (A) The frequency of mutations of FAT1 in four types of squamous cell carcinomas (ESCC, esophageal squamous cell carcinoma; HNSCC, head and neck squamous cell carcinoma; LSCC, lung squamous cell carcinoma; OSCC, oral squamous cell carcinoma) in the TCGA database. (B) Overall and representative images of FAT1 expression in tumor tissues (T) and adjacent non-tumor tissues (N) from paraffin-embedded formalin-fixed ESCC tissue microarrays containing 76 tumors and corresponding non-tumor tissues by IHC. Left panel: magnification x10 (scale bar, $4 \mu \mathrm{m}$ ); right upper panel: magnification x200 (scale bar, $100 \mu \mathrm{m}$ ); right lower panel: statistical analysis of FAT1 protein level based on TMA data. FAT1, FAT atypical cadherin 1. 


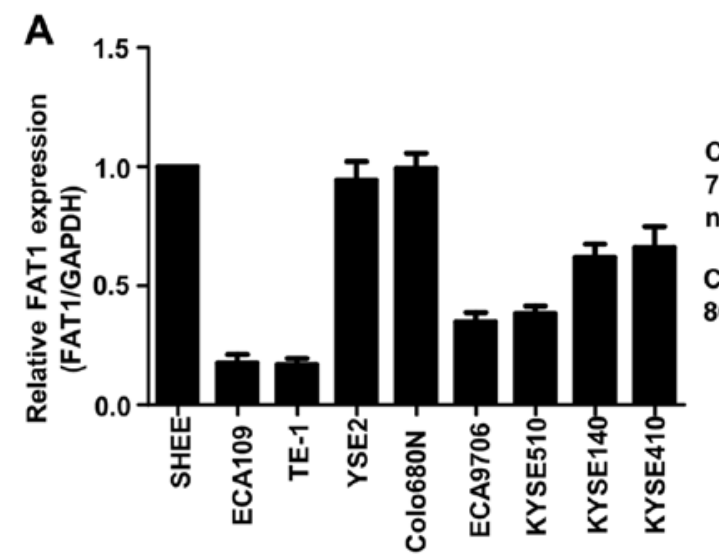

B
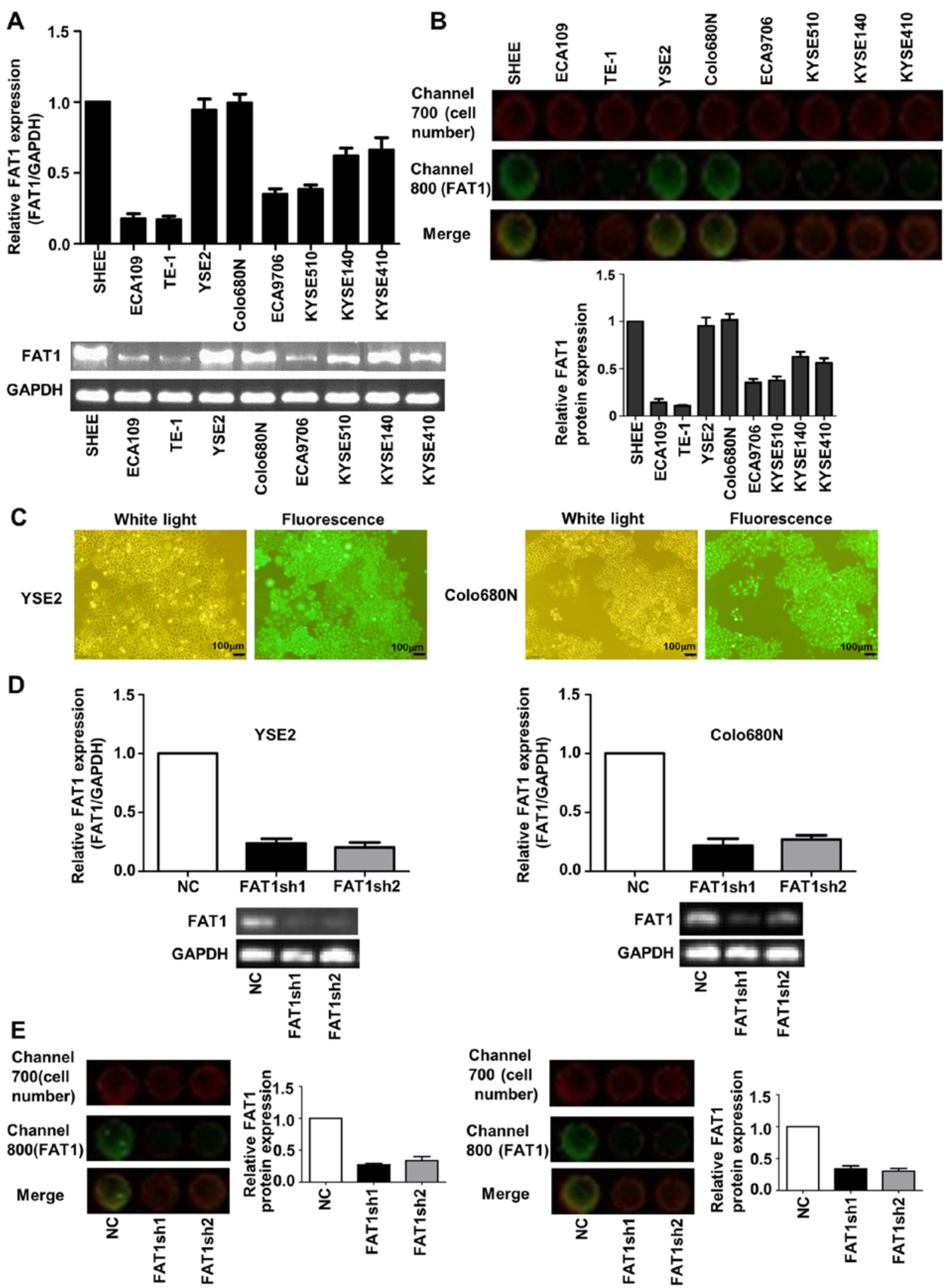

Figure 2. Verification of the knockdown efficiency of FAT1 in YSE2 and Colo680N cells. (A) The mRNA expression pattern of FAT1 in non-transformed esophageal epithelial SHEE cells and 8 ESCC cell lines as detected by qPCR (upper panel) and RT-PCR (Lower panel). (B) Upper panel: FAT1 protein level in non-transformed esophageal epithelial SHEE cells and 8 ESCC cell lines as detected by in-cell western assay. Channel 700 represents cell number and channel 800 represents FAT1. The merge represents the protein expression of FAT1 in these cells. Lower panel: Quantification of the protein level of FAT1 in various ESCC cell lines. (C) Examination of the transfection efficiency of the FAT1shRNA plasmid into the YSE2 and Colo680N cells by fluorescence microscopy (scale bar, $100 \mu \mathrm{m}$ ). (D) Knockdown efficiency of FAT1 in YSE2 and Colo680N cells was verified by qPCR (upper panel) and RT-PCR (lower panel). (E) Knockdown efficiency of FAT1 in YSE2 (left panel) and Colo680N cells (right panel) was verified in-cell western assay. Channel 700 represents cell number and channel 800 represents FAT1. The merge represents the protein expression of FAT1 in these cells. All experiments were repeated three times independently. FAT1, FAT atypical cadherin 1. 
A
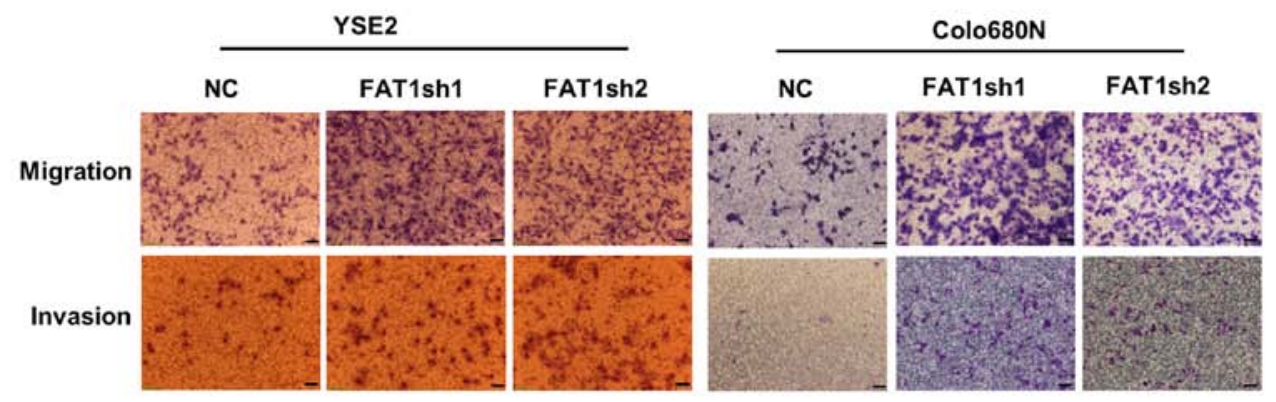

B
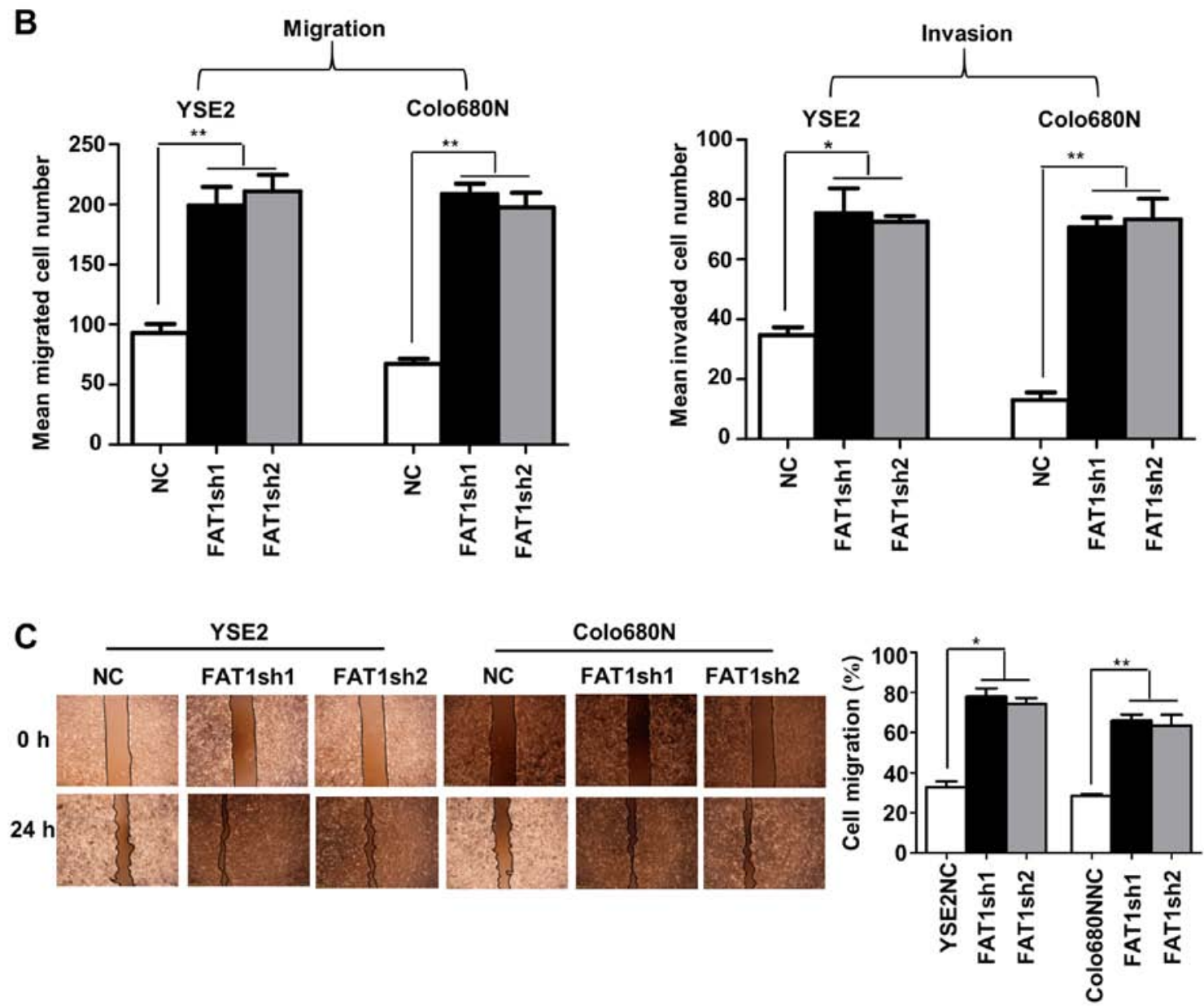

Figure 3. Silencing of FAT1 accelerates cell migration and invasion in YSE2 and Colo680N cells. (A) Silencing of FAT1 promoted the migration and invasion of YSE2 and Colo680N cells. Representative images of the migration and invasion assays are shown (scale bar, $100 \mu \mathrm{m}$ ). (B) Histograms showing that FAT1 inhibition promoted the ability of cell migration and invasion. (C) Cell migration as monitored by wound healing assay was carried out in YSE2 and Colo680N cells. The wound area was calculated using ImageJ software. All experiments were repeated three times independently. ${ }^{*} \mathrm{P}<0.05,{ }^{* * *} \mathrm{P}<0.01$. FAT1, FAT atypical cadherin 1.

$A F M$. In the present study, AFM was used to visualize the morphology of YSE2 and Colo680N FAT1-knockdown cells in comparison to the corresponding control groups, respectively. The results demonstrated that the cells became relatively thinner following FAT1 knockdown. In addition, we detected the roughness of the cell membrane surface. The results showed that, although the cell surface roughness in the FAT1-knockdown cells had no statistical difference when compared with the NC group, there was a downward trend. The results indicate that the cell surface may be smoother after knockdown of FAT1 (Fig. 4).
Furthermore, compared to the NC groups, the adhesive force was significantly reduced (YSE2NC, $1200 \pm 300 \mathrm{pN}$ vs. FAT1shRNA, 480 \pm 200 pN; Colo680NNC, $1400 \pm 400$ pN vs. FAT1shRNA, $560 \pm 230 \mathrm{pN}$ ), while theelasticity force was markedly increased (YSE2NC, 3.9 $\pm 0.7 \mathrm{MPa}$ vs. FAT1shRNA, $19 \pm 6.3 \mathrm{MPa}$; Colo680NNC, 4.2 $\pm 1.3 \mathrm{MPa}$ vs. FAT1shRNA, 26 $\pm 5.5 \mathrm{MPa}$ ) in the YSE2-FAT1shRNA and Colo680N-FAT1shRNA groups, and the difference was statistically significant (Fig. 5). Taken together, these results suggest that FAT1 may affect cell microscopic morphology and mechanical properties consequently impacting ESCC cell migration and invasion ability. 
Table I. Information concerning the 125 patients in the tissue microarray study.

\begin{tabular}{|c|c|}
\hline Characteristics & No. of cases $(\mathrm{N}=125)$ \\
\hline \multicolumn{2}{|l|}{ Age (years) } \\
\hline$<60$ & 69 \\
\hline$\geq 60$ & 56 \\
\hline \multicolumn{2}{|l|}{ Sex } \\
\hline Male & 86 \\
\hline Female & 39 \\
\hline \multicolumn{2}{|l|}{ Smoking } \\
\hline No & 46 \\
\hline Yes & 79 \\
\hline \multicolumn{2}{|l|}{ Drinking } \\
\hline No & 81 \\
\hline Yes & 44 \\
\hline \multicolumn{2}{|l|}{ Family history } \\
\hline No & 97 \\
\hline Yes & 28 \\
\hline \multicolumn{2}{|l|}{ Differentiation } \\
\hline High & 4 \\
\hline Middle & 89 \\
\hline Low & 32 \\
\hline \multicolumn{2}{|l|}{ T Classification } \\
\hline $\mathrm{T} 1$ & 10 \\
\hline $\mathrm{T} 2$ & 27 \\
\hline $\mathrm{T} 3$ & 88 \\
\hline $\mathrm{T} 4$ & 0 \\
\hline \multicolumn{2}{|l|}{$\mathrm{N}$ classification } \\
\hline $\mathrm{N}<1$ & 47 \\
\hline $\mathrm{N} \geq 1$ & 78 \\
\hline \multicolumn{2}{|l|}{ TNM stage } \\
\hline $\mathrm{I}$ & 6 \\
\hline II & 50 \\
\hline III & 68 \\
\hline IV & 1 \\
\hline
\end{tabular}

\section{Discussion}

As one of the members of the cadherin family, FAT atypical cadherin 1 (FAT1) is regarded as a key molecule that regulates cellular growth, migration and orientation. The effect of FAT1 on tumor occurrence and development is still in discussion (27). The dual role of FAT1 in human cancer development has been reported as it functions as both a tumor-suppressor gene as well as an oncogene $(9-11,28)$. FAT1 was first deemed to posses a tumor suppressive function in Drosophila melanogaster by regulating the Salvador/Warts/Hippo signaling pathway $(29,30)$. In glioblastoma multiforme, colorectal cancer and head and neck cancer, FAT1 was identified as a tumor suppressor, for which somatic mutations lead to aberrant Wnt signaling pathway activation (12). In breast carcinoma, suppression of FAT1 expression was found to promote breast cancer cell invasion (31). However, in hepatocellular carcinoma, FAT1 acts as a tumor promoter and promotes the proliferation and migration as well as inhibits apoptosis (11). The possible switch of FAT1 from an oncogene to an oncogenesis-preventive gene may be due to the specificity of the tissues and organs and the complexity of the signaling pathways. In our previous study, we identified a novel role of FAT1 in inhibiting tumor growth and EMT occurrence in ESCC by means of disruption of the MAPK/ERK pathway (8). In the present study, we further identified the tumor-suppressor function of FAT1 in light of the changes in the morphologic and biomechanical properties of the cells using AFM.

A change in cell mechanical properties can affect the body's physiological function and cause disease (32); in particular, cell mechanical properties play an important role in the study of human cancer $(33,34)$. In recent years, more and more research has shown that AFM can be used as a tool for the detection of the biological behaviors of tumor cells and for assessment of antitumor efficacy (35). Cell adhesion and elasticity force may reflect the cell membrane and cytoskeleton mechanics state and are associated with cellular deformability (36). Increased cell adhesion strength and decreased elasticity lead to deformation capacity reduction. Tumor cells need deformation to complete migration, invasion and a series of biological behaviors (37). Propofol was found to decrease the migratory ability by influencing the cell cytoskeleton in cervical cancer cell lines (38). Lian et al reported that artesunate attenuates cellular migration and invasion by affecting cellular mechanical properties in glioma (39). In addition, studies have shown that the mechanical properties of cells and tissues as determined by AFM can be used as markers for the diagnosis of various pathological conditions such as cancer, arthritis, osteoporosis (40), pulmonary fibrosis (41), blood and cardiovascular pathologies (40). Therefore, we speculate that AFM may serve as a means of clinical laboratory examination in the future. In the present study, we detected cell adhesive force and cell elasticity force by AFM and found that suppression of endogenous expression of FAT1 led to a decrease in cell adhesive force and an increase in cell elasticity force compared with the control groups.

Although FAT1 was recently implicated as a tumor suppressor or an oncogene in other cancers, its roles in ESCC are limited. In our previous research, we found that FAT1 was one of the significantly mutated genes in ESCC and FAT1 expression was decreased in ESCC tissues compared with that noted in matched normal adjacent tissues (8). In the present study, we verified that FAT1 knockdown effectively accelerated cell migration and invasion. Moreover, the impact of FAT1 disruption on the cellular mechanical properties was also evaluated by AFM. The cytoskeleton consists of microtubules, microfilaments and microvilli, which determines the cell morphology and biomechanical characteristics under various physiological and pathological statuses (42). Yao et al showed that MARVELD1, a potential tumor suppressor, increased the length of microvilli and suppressed EMT in non-small cell lung cancer (43). In breast cancer MCF-7 cell lines, rhBMP-2 was found to promote EMT progression and AFM observation showed that the MCF-7 cells became narrower and flatter, with 


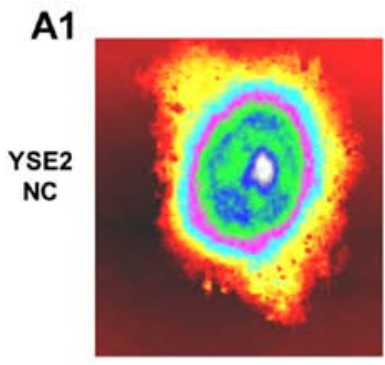

A2

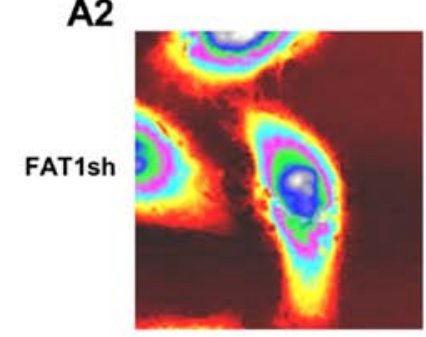

A3

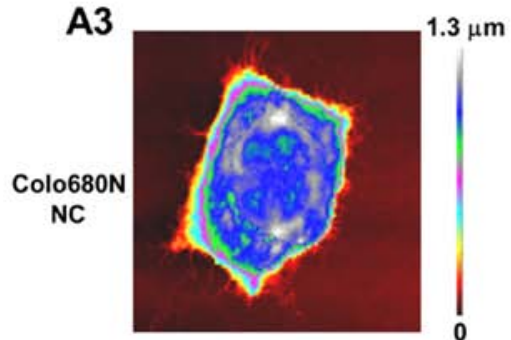

A4

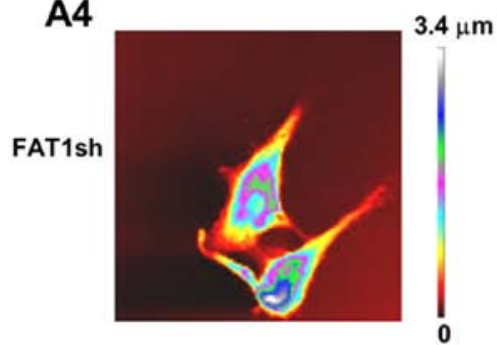

D。

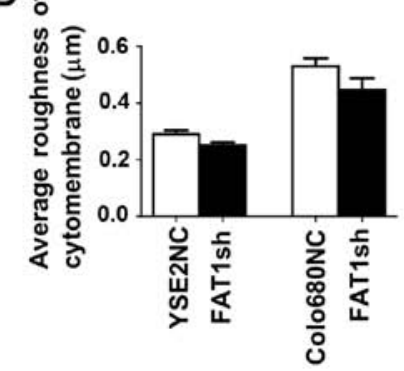

B1

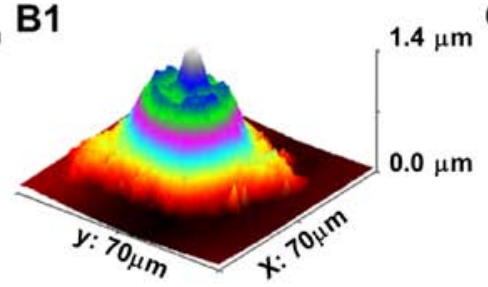

C1

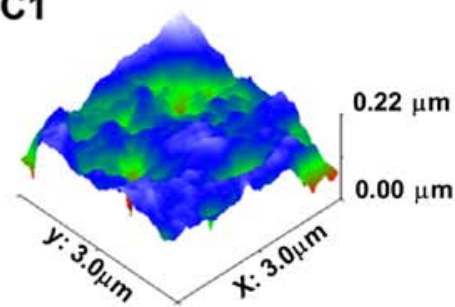

C2

B2
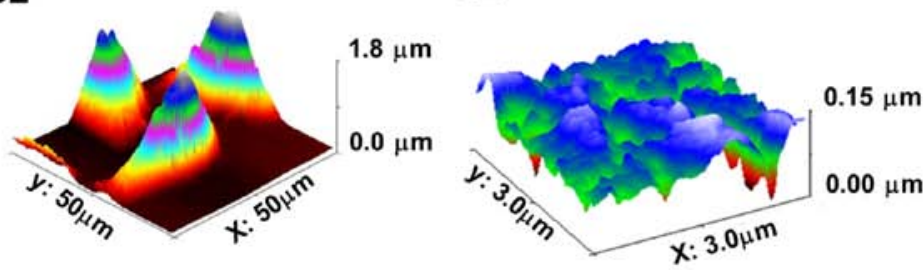

C3

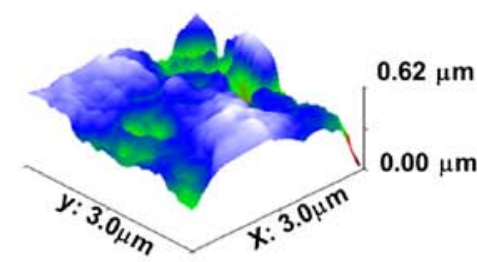

C4

B4
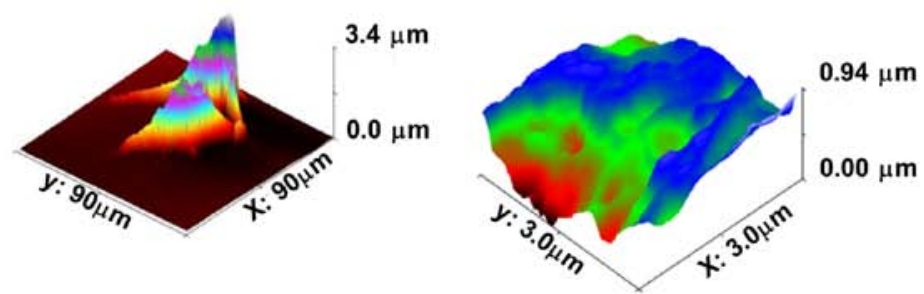

Figure 4. The morphological images of YSE2 and Colo680N cells following FAT1 knockdown and the matched negative control groups by atomic force microscopy (AFM). (A) The 2D cell morphology of YSE2 and Colo680N cells following FAT1 knockdown and the matched negative control (NC) groups by AFM. A1, NC group (YSE2 cells); A2, FAT1-knockdown group (YSE2 cells); A3, NC group (Colo680N cells); A4, FAT1-knockdown group (Colo680N cells). (B) 3D cell morphology. B1, NC group (YSE2 cells); B2, FAT1-knockdown group (YSE2 cells); B3, NC group (Colo680N cells); B4, FAT1-knockdown group (Colo680N cells). (C) The cell ultra-structure of YSE2 and Colo680N cells of the FAT1-knockdown and matched negative groups by AFM. C1, NC group (YSE2 cells); C2, FAT1-knockdown group (YSE2 cells); C3, NC group (Colo680N cells); C4, FAT1-knockdown group (Colo680N cells). (D) The statistical histogram of average roughness of the cytomembrane of ESCC cells with or without FAT1 knockdown. All experiments were repeated three times independently. ${ }^{*} \mathrm{P}<0.05,{ }^{* *} \mathrm{P}<0.01$. FAT1, FAT atypical cadherin 1.

lamellipodia formation following rhBMP-2 treatment (44). Our previous study showed that FAT1 prevented EMT and inhibited the migration and invasion of ESCC cells. Our present study showed that FAT1 may affect cytoskeleton proteins, and therefore alter the ability of cell migration and invasion. The specific mechanism will be explored in subsequent research.
In conclusion, the present study showed that FAT1 inhibited cell migration and invasion by affecting the cellular mechanical properties of ESCC cells. The present findings aid in our understanding of the potential mechanisms that drive the development of ESCC and may provide new insight concerning the association between FAT1 and ESCC. 

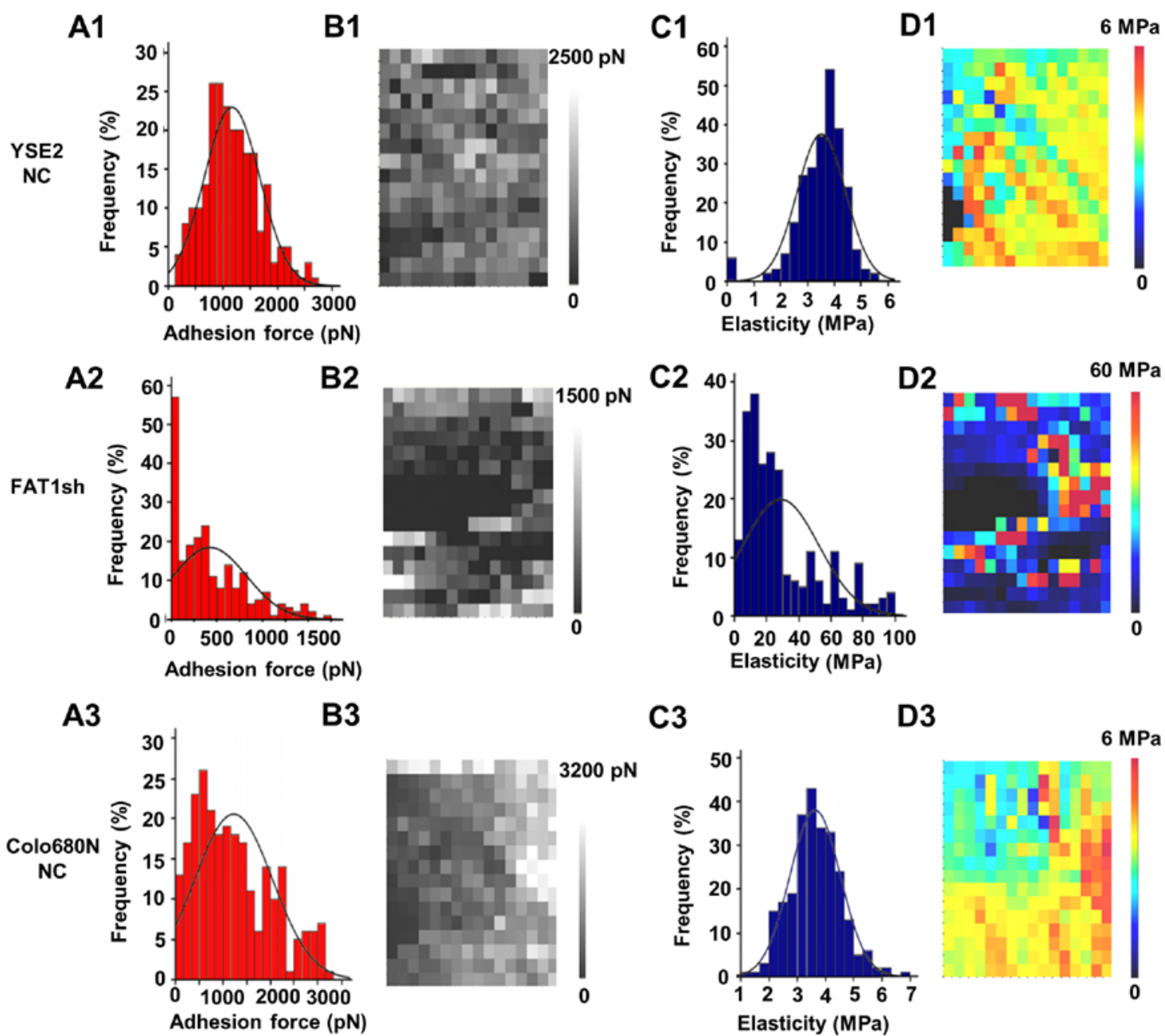

C3
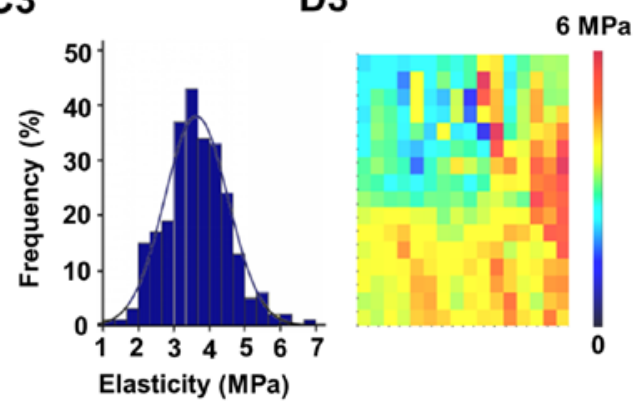

A4

B4

\section{C4}
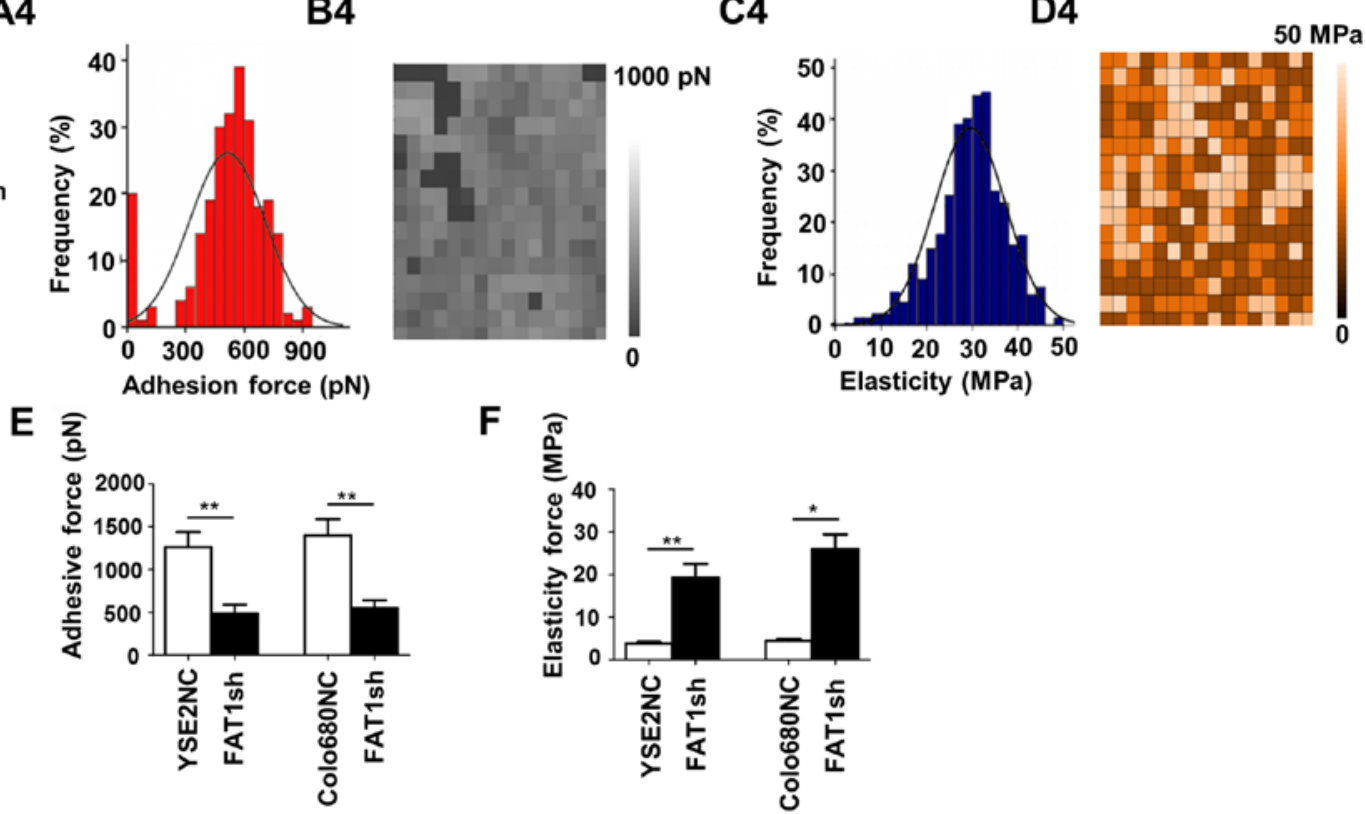

Figure 5. AFM force-distance curve analyses to detect the adhesive force and elasticity of YSE2 and Colo680N cells in the FAT1-knockdown and matched negative groups. (A) Adhesion force histograms showing the adhesive force and elasticity of YSE2 and Colo680N cells in the FAT1-knockdown and matched negative control (NC) groups by atomic force microscopy (AFM). A1, NC group (YSE2 cells); A2, FAT1-knockdown group (YSE2 cells); A3, NC group (Colo680N cells); A4, FAT1-knockdown group (Colo680N cells). (B) Adhesion force map of the same cell-surface area. B1, NC group (YSE2 cells); B2, FAT1-knockdown group (YSE2 cells); B3, NC group (Colo680N cells); B4, FAT1-knockdown group (Colo680N cells). (C) Elasticity histogram. C1, NC group (YSE2 cells); C2, FAT1-knockdown group (YSE2 cells); C3, NC group (Colo680N cells); C4, FAT1-knockdown group (Colo680N cells). (D) Elasticity map of the same cell-surface area. D1, NC group (YSE2 cells); D2, FAT1-knockdown group (YSE2 cells); D3, NC group (Colo680N cells); D4,FAT1-knockdown group (Colo680N cells). (E) Statistical histogram showing the adhesive force of ESCC cells with or without FAT1 knockdown. (F) Statistical histogram of the elasticity force of ESCC cells with or without FAT1 knockdown. All experiments were repeated three times independently. ${ }^{~} \mathrm{P}<0.05,{ }^{* *} \mathrm{P}<0.01$. FAT1, FAT atypical cadherin 1. pN, picoNewton $\left(10^{-12} \mathrm{~N}\right)$; MPa, mega Pascal $\left(10^{6} \mathrm{~Pa}\right)$. 


\section{Acknowledgements}

We would like to thank the patients with ESCC and their families for participation. We would also like to thank Dr Xun Huang (Department of Materials Science and Engineering, Jinan University) for his contributions to the determination of cell mechanics properties.

\section{Funding}

The present study was supported through funding from the National Natural Science Foundation of China (81330063 to $\mathrm{YC}, 81672768$ to $\mathrm{XC}, 81602176$ to $\mathrm{RS}, 81602458$ to $\mathrm{CC}$ and 81502135 to $\mathrm{PK})$, Natural Science Foundation of Shanxi Province (201601D202107 to RS and 201701D221249 to $\mathrm{XH}$ ), Startup Foundation for Doctors of Shanxi Medical University (03201006 to XH), Youth Foundation of Shanxi Medical University (057487 to XH) and The 331 Early Career Researcher Grant of Shanxi Medical University (201219 to XH).

\section{Availability of data and materials}

The datasets of IHC used and/or analyzed during the current study are available from the corresponding author on reasonable request. The datasets of FAT1 mutation in squamous cell carcinomas were obtained from the TCGA database. Other datasets generated or analyzed during this study are included in this published article.

\section{Authors' contributions}

$\mathrm{XC}, \mathrm{PK}$ and $\mathrm{XH}$ were responsible for the design of the experiment and the writing of the manuscript. $\mathrm{MZ}$ and $\mathrm{YC}$ made the editor of the manuscript. YZ performed the IHC of the ESCC tissue. YQ and HC analyzed and interpreted the data of ESCC patient. XH, JY, YB and TY performed the RT-qPCR and western blot analysis of the experiment. RS, JY and YM were major contributors in the determination of cell mechanics properties. XH, LZ, YL and GL performed the migration and invasion of cells. All authors read and approved the final manuscript.

\section{Ethics approval and consent to participate}

All experimental protocols were approved by the Ethics Committee of Shanxi Medical University. All samples were obtained before treatment according to the guidelines of the local ethics committees.

\section{Consent for publication}

Written informed consent was received from all participants.

\section{Competing interests}

The authors declare that they have no competing interests.

\section{References}

1. Wheeler JB and Reed CE: Epidemiology of esophageal cancer. Surg Clin North Am 92: 1077-1087, 2012.
2. Chen W, Zheng R, Baade PD, Zhang S, Zeng H, Bray F, Jemal A, Yu XQ and He J: Cancer statistics in China, 2015. CA Cancer J Clin 66: 115-132, 2016.

3. Ferlay J, Soerjomataram I, Dikshit R, Eser S, Mathers C, Rebelo M, Parkin DM, Forman D and Bray F: Cancer incidence and mortality worldwide: Sources, methods and major patterns in GLOBOCAN 2012. Int J Cancer 136: E359-E386, 2015.

4. Pennathur A, Gibson MK, Jobe BA and Luketich JD: Oesophageal carcinoma. Lancet 381: 400-412, 2013.

5. Ferlay J, Shin HR, Bray F, Forman D, Mathers C and Parkin DM: Estimates of worldwide burden of cancer in 2008: GLOBOCAN 2008. Int J Cancer 127: 2893-2917, 2010.

6. Zhang L, Zhou Y, Cheng C, Cui H, Cheng L, Kong P, Wang J, Li Y, Chen W, Song B, et al: Genomic analyses reveal mutational signatures and frequently altered genes in esophageal squamous cell carcinoma. Am J Hum Genet 96: 597-611, 2015.

7. Cheng C, Zhou Y, Li H, Xiong T, Li S, Bi Y, Kong P, Wang F, Cui $\mathrm{H}, \mathrm{Li} \mathrm{Y}$, et al: Whole-genome sequencing reveals diverse models of structural variations in esophageal squamous cell carcinoma. Am J Hum Genet 98: 256-274, 2016.

8. Hu X, Zhai Y, Kong P, Cui H, Yan T, Yang J, Qian Y, Ma Y, Wang F, Li H, et al: FAT1 prevents epithelial mesenchymal transition (EMT) via MAPK/ERK signaling pathway in esophageal squamous cell cancer. Cancer Lett 397: 83-93, 2017.

9. Sadeqzadeh E, de Bock CE, Zhang XD, Shipman KL, Scott NM, Song C, Yeadon T, Oliveira CS, Jin B, Hersey P, et al: Dual processing of FAT1 cadherin protein by human melanoma cells generates distinct protein products. J Biol Chem 286: 28181-28191, 2011.

10. Kim KT, Kim BS and Kim JH: Association between FAT1 mutation and overall survival in patients with human papillomavirus-negative head and neck squamous cell carcinoma. Head Neck 38 (Suppl 1): E2021-E2029, 2016.

11. Valletta D, Czech B, Spruss T, Ikenberg K, Wild P, Hartmann A, Weiss TS, Oefner PJ, Müller M, Bosserhoff AK and Hellerbrand C: Regulation and function of the atypical cadherin FAT1 in hepatocellular carcinoma. Carcinogenesis 35: 1407-1415, 2014.

12. Morris LG, Kaufman AM, Gong Y, Ramaswami D, Walsh LA, Turcan S, Eng S, Kannan K, Zou Y, Peng L, et al: Recurrent somatic mutation of FAT1 in multiple human cancers leads to aberrant Wnt activation. Nat Genet 45: 253-261, 2013.

13. Settakorn J, Kaewpila N, Burns GF and Leong AS: FAT, E-cadherin, beta catenin, HER 2/neu, Ki67 immuno-expression, and histological grade in intrahepatic cholangiocarcinoma. J Clin Pathol 58: 1249-1254, 2005.

14. Shi X, Zhang X, Xia T and Fang X: Living cell study at the single-molecule and single-cell levels by atomic force microscopy. Nanomedicine 7: 1625-1637, 2012.

15. Zhang L, Yang F, Cai JY, Yang PH and Liang ZH: In-situ detection of resveratrol inhibition effect on epidermal growth factor receptor of living MCF-7 cells by atomic force microscopy. Biosens Bioelectron 56: 271-277, 2014.

16. Tang J, Jiang C, Xiao X, Fang Z, Li L, Han L, Mei A, Feng Y, Guo Y, Li H and Jiang W: Changes in red blood cell membrane structure in G6PD deficiency: An atomic force microscopy study. Clin Chim Acta 444: 264-270, 2015.

17. Kaul-Ghanekar R, Singh S, Mamgain H, Jalota-Badhwar A, Paknikar KM and Chattopadhyay S: Tumor suppressor protein SMAR1 modulates the roughness of cell surface: Combined AFM and SEM study. BMC Cancer 9: 350, 2009.

18. Cross SE, Jin YS, Rao J and Gimzewski JK: Nanomechanical analysis of cells from cancer patients. Nat Nanotechnol 2: 780-783, 2007.

19. Shi R, Cui H, Bi Y, Huang X, Song B, Cheng C, Zhang L, Liu J, He C, Wang F, et al: Artesunate altered cellular mechanical properties leading to deregulation of cell proliferation and migration in esophageal squamous cell carcinoma. Oncol Lett 9: 2249-2255, 2015.

20. Gao YB, Chen ZL, Li JG, Hu XD, Shi XJ, Sun ZM, Zhang F, Zhao ZR, Li ZT, Liu ZY, et al: Genetic landscape of esophageal squamous cell carcinoma. Nat Genet 46: 1097-1102, 2014.

21. Lin DC, Hao JJ, Nagata Y, Xu L, Shang L, Meng X, Sato Y, Okuno Y, Varela AM, Ding LW, et al: Genomic and molecular characterization of esophageal squamous cell carcinoma. Nat Genet 46: 467-473, 2014.

22. Song Y, Li L, Ou Y, Gao Z, Li E, Li X, Zhang W, Wang J, Xu L, Zhou Y, et al: Identification of genomic alterations in oesophageal squamous cell cancer. Nature 509: 91-95, 2014.

23. Gao J, Aksoy BA, Dogrusoz U, Dresdner G, Gross B, Sumer SO, Sun Y, Jacobsen A, Sinha R, Larsson E, et al: Integrative analysis of complex cancer genomics and clinical profiles using the cBioPortal. Sci Signal 6: pl1, 2013. 
24. Cerami E, Gao J, Dogrusoz U, Gross BE, Sumer SO, Aksoy BA, Jacobsen A, Byrne CJ, Heuer ML, Larsson E, et al: The cBio cancer genomics portal: An open platform for exploring multidimensional cancer genomics data. Cancer Discov 2: 401-404, 2012.

25. Cancer Genome Atlas Research Network: Comprehensive genomic characterization of squamous cell lung cancers. Nature 489: 519-525, 2012.

26. Pickering CR, Zhang J, Yoo SY, Bengtsson L, Moorthy S, Neskey DM, Zhao M, Ortega Alves MV, Chang K, Drummond $\mathrm{J}$, et al: Integrative genomic characterization of oral squamous cell carcinoma identifies frequent somatic drivers. Cancer Discov 3: 770-781, 2013.

27. Katoh M: Function and cancer genomics of FAT family genes (Review). Int J Oncol 41: 1913-1918, 2012.

28. Tanoue T and Takeichi M: New insights into fat cadherins. J Cell Sci 118: 2347-2353, 2005

29. Bennett FC and Harvey KF: Fat cadherin modulates organ size in Drosophila via the Salvador/Warts/Hippo signaling pathway. Curr Biol 16: 2101-2110, 2006.

30. Reddy BV and Irvine KD: The fat and warts signaling pathways: New insights into their regulation, mechanism and conservation. Development 135: 2827-2838, 2008.

31. Lee S, Stewart S, Nagtegaal I, Luo J, Wu Y, Colditz G, Medina D and Allred DC: Differentially expressed genes regulating the progression of ductal carcinoma in situ to invasive breast cancer. Cancer Res 72: 4574-4586, 2012.

32. Lee GY and Lim CT: Biomechanics approaches to studying human diseases. Trends Biotechnol 25: 111-118, 2007.

33. Guck J, Schinkinger S, Lincoln B, Wottawah F, Ebert S, Romeyke M, Lenz D, Erickson HM, Ananthakrishnan R, Mitchell D, et al: Optical deformability as an inherent cell marker for testing malignant transformation and metastatic competence. Biophys J 88: 3689-3698, 2005.

34. Suresh S: Biomechanics and biophysics of cancer cells. Acta Biomater 3: 413-438, 2007.

35. Cai X, Gao S, Cai J, Wu Y and Deng H: Artesunate induced morphological and mechanical changes of Jurkat cell studied by AFM. Scanning 31: 83-89, 2009.
36. Fletcher DA and Mullins RD: Cell mechanics and the cytoskeleton. Nature 463: 485-492, 2010.

37. Kumar S and Weaver VM: Mechanics, malignancy, and metastasis: The force journey of a tumor cell. Cancer Metastasis Rev 28: 113-127, 2009.

38. Zhang F, Wang C, Cui Y, Li S, Yao Y, Ci Y, Wang J, Hou W, Wu A and Li E: Effects of propofol on several membrane characteristics of cervical cancer cell lines. Cell Physiol Biochem 40: 172-182, 2016.

39. Lian S, Shi R, Huang X, Hu X, Song B, Bai Y, Yang B, Dong J, $\mathrm{Du} \mathrm{Z}$, Zhang Y, et al: Artesunate attenuates glioma proliferation, migration and invasion by affecting cellular mechanical properties. Oncol Rep 36: 984-990, 2016.

40. Khalili AA and Ahmad MR: A review of cell adhesion studies for biomedical and biological applications. Int J Mol Sci 16: $18149-18184,2015$

41. Siamantouras E, Hills CE, Squires PE and Liu KK: Quantifying cellular mechanics and adhesion in renal tubular injury using single cell force spectroscopy. Nanomedicine 12: 1013-1021, 2016.

42. Fuchs E and Cleveland DW: A structural scaffolding of intermediate filaments in health and disease. Science 279: 514-519, 1998.

43. Yao Y, Shi M, Liu S, Li Y, Guo K, Ci Y, Liu W and Li Y: MARVELD1 modulates cell surface morphology and suppresses epithelial-mesenchymal transition in non-small cell lung cancer. Mol Carcinog 55: 1714-1727, 2016.

44. Wang D, Huang P, Zhu B, Sun L, Huang Q and Wang J: Induction of estrogen receptor $\alpha-36$ expression by bone morphogenetic protein 2 in breast cancer cell lines. Mol Med Rep 6: 591-596, 2012.

(i) $\odot$ This work is licensed under a Creative Commons Attribution-NonCommercial-NoDerivatives 4.0 International (CC BY-NC-ND 4.0) License. 